\title{
A New Carrier for Advanced Cosmeceuticals
}

\author{
Pierfrancesco Morganti ${ }^{1,2, *}$ and Maria-Beatrice Coltelli ${ }^{3}$ (i) \\ 1 Campania University, L. Vanvitelli, Dermatol Unit, 80100 Naples, Italy \\ 2 Interuniversity Consortium of Materials Science and Technology (INSTM), c/o Department of Civil and \\ Industrial Engineering, University of Pisa, 56122 Pisa, Italy \\ 3 Department of Civil and Industrial Engineering, University of Pisa, 56122 Pisa, Italy; \\ maria.beatrice.coltelli@unipi.it \\ * Correspondence: pierfrancesco.morganti@mavicosmetics.it
}

Received: 3 January 2019; Accepted: 27 January 2019; Published: 14 February 2019

Abstract: Cosmetic products are generally formulated as emulsions, ointments, solutions or powders containing active ingredients. According to EU legislation, a cosmetic product is "any substance or preparation intended to be placed in contact with the various external parts of the human body with a view exclusively or mainly to cleaning, perfuming them, changing their appearance, and/or correcting body odors and/or protecting them or keeping them in good conditions". However, science advancement in both active carriers and ingredients has streamlined the process through which many cosmetic products by their delivery systems can induce modifications on the skin physiology. This is the reason why Reed and Kligman redefined these products as "cosmeceuticals", which refers to the combination of cosmetics and pharmaceuticals. Until recently, the term of cosmeceuticals has not had legal significance. The so-called cosmeceuticals, in fact, may induce modifications on the skin physiology, modifying, for example, transepidermal water loss, keratinocytes cohesion and turnover, modulating the inflammatory cascade, and/or altering the surface microbiota by the activity of the preservatives content. For these reasons, they are claimed to have medical or drug-like benefits. Naturally, their effectiveness on minor skin disorders or mild skin abnormalities has to be shown by in vitro and in vivo studies. On the other hand, their formulations contain emulsifiers, preservatives, and other chemicals which, by their cumulative use, may provoke side effects, such as allergic and/or sensitization phenomena. Moreover, many ingredients and packaging for such products are not biodegradable. In this study, we would like to introduce an innovative category of cosmeceuticals made by biodegradable nonwoven tissues. These cosmeceutical tissues, produced through the use of natural fibers, may bind different active ingredients and therefore become effective as antibacterial, anti-inflammatory, sun-protective, whitening, or anti-aging products, depending on the ingredient(s) used. Differently from the usual cosmetics, they do not contain preservatives, emulsifiers, colors, and other chemicals. They can be applied as dried tissue on wet skin, remaining in loco for around $30 \mathrm{~min}$, slowly releasing the active ingredients entrapped into the fibers. It is interesting to underline that the tissue, acting as a carrier, has its own effectiveness via chitin and lignin polymers with an antibacterial and anti-inflammatory activity. When hydrolyzed by the human microbiota enzymes, they give rise to ingredients used as cell nourishment or energy. This paper will review part of the scientific research results, supporting this new category of biodegradable cosmetic products known as facial mask sheets.

Keywords: cosmeceuticals; cosmetics; microbiome; facial mask sheet; chitin nanofibrils; lignin

\section{Introduction}

Cosmetics and toiletries represent a highly diversified multidisciplinary field involving many scientific sectors, such as material physic chemistry, cell biology, bioethics, regulatory affairs, business 
administration, and commercialization transition. The products are generally formulated under the form of emulsion, ointment, gel, solution, or powder containing different active ingredients characterizing their defined and declared properties [1]. Unfortunately, all the cosmetics are based on water use and therefore prone to microbial contamination. Thus, they must be preserved by specific ingredients capable of killing bacteria and other microorganisms. Bacteria, in fact, spoil the formulation and modify its structure, provoking the production of compounds often dangerous for skin and human health in general. Microbial contamination may occur not only during the production, packaging, and distribution processes, but also in consumer correspondence or through many other sources over a product's life-thus leading to the necessity to preserve cosmetic products from microorganisms found in cosmetics carbon and nitrogen as nutrients that can grow on a moderate temperature in the presence of water and organic substrates. These substrates, such as amino acids, vitamins, minerals, and free fatty acids, are used as functional molecules for different cosmetic products and are all ingredients that are used from microorganisms as sources of food and energy. They may also be transformed into toxic compounds dangerous for human health. However, the commercial success of any cosmetic product is impaired because of the modification of the functional ingredients in its main properties [2]. Thus, it would be necessary to know what may occur among the different molecules, as well as what emulsifier is used, as that is an important factor in determining the distribution profile of the active ingredient. However, prior to introducing the designed ingredients at the laboratory level, many other factors have to be considered before giving the right functionality to the final formulation (apart from its stability and aesthetic property). These factors include the compatibility of ingredients, their microbiological and regulatory compliance, as well as ingredient availability, quality, and cost. Moreover, the cosmetic product has to be easy to manufacture, market, and ship, as it is also covered by patent infringements [2].

Apart from the uses of one or more preservatives, emulsifier compounds are also necessary to obtain emulsion - the most common type of delivery system used for cosmetic products—or to solubilize the fragrance, which is generally represented by essential oils that spread uniformly and quickly via powder and colors over skin.

It is important to remember that preservatives and emulsifiers could be irritating for the skin, causing allergy or sensitization phenomena, because of their specific biological characteristics and physicochemical activities. In any case, the correct use of emulsifiers permits the chemist to formulate their water solutions, dispersions, or emulsions made by oily, waxy, and powdery substances [3]. In fact, being both hydrophilic and lipophilic, emulsifiers are compounds that are used to reduce surface tension, are indispensable to disperse oil in water, and therefore can make emulsions or solubilize fragrances.

\section{Cosmetic Products}

According to EU legislation [4,5], cosmetic products are represented by "any substance or preparation intended to be placed in contact with the various external parts of the human body with a view exclusively or mainly to cleaning, perfuming them, changing their appearance and/or correcting body odors and/or protecting them or keeping them in good conditions" [4,5]. While the scientific advancement in active carriers and ingredients streamlines the cosmetic delivery system and functionality, so-called cosmeceuticals could be able to induce modifications on the skin physiology, enhancing product effectiveness [6]. However, until today, this term (cosmeceuticals), coined by Reed in 1962 [7] and redefined by Kligman [8] about 30 years later, remains without any legal significance. Furthermore, any category of cosmetics, including cosmeceuticals, may induce modifications of skin [9] by the activity of emulsifiers, which modulate transepidermal water loss, as well as keratinocytes cohesion and turnover. Moreover, the current cosmetic products or cosmeceuticals $[7,10]$ that claim to have drug-like benefits are able to regulate the inflammatory cascade and/or repair diseased skin. Unfortunately, these products also alter the surface microbiome [11]. Moreover, they may have undesirable side effects because of undesired interactions with preservatives, fragrances, and other 
chemicals used for their formulation. For these reasons, cosmetic/cosmeceutical effectiveness and safety must be controlled in vitro on cell cultures and in vivo on skin (healthy or affected by minor disorders or mild abnormalities) by methodologies scientifically and clinically correct $[12,13]$. In reality, although the frequency of cosmetic adverse serious events reported by EU and USA guidelines seems to be low $[14,15]$, the cross allergy and human sensitization phenomena connected with the activity of preservatives, emulsifiers, flavoring, colors, and other chemicals used for cosmetic, food, household, and professional products are increasing worldwide with the risk of chronic diseases [16]. What is interesting to underline on the class of preservatives more often present in many consumer products is that on the one hand, the mass media daily war against the 4-hydroxy benzoic acid and its derivatives, known as parabens, also if they are commonly found in various vegetable foods such as onion, carrots, peaches, etc., and posing a negligible risk to endocrine systems $[17,18]$, and on the other hand, the great use and consume of the thiazolinone derivatives, biologically dangerous chemicals (almost unknown to mass media and consumers), which have provoked many allergic phenomena worldwide [19-21]. However, the massive use of these and other chemicals in everyday life must be drastically reduced if we wish to maintain our health in good condition and to preserve the environment and biodiversity of our planet.

This paper aims to introduce an innovative category of cosmeceuticals made by biodegradable nonwoven tissues made by chitin nanofibrils and nanolignin. They can be produced and distributed at the dry state. These tissue-carriers produced as facial mask sheets (Figure 1) consist of natural fibers able to strictly bind and release the entrapped active ingredients at different doses and time. Thanks to the carrier and ingredient functionality, these innovative products can be used, for example, as antibacterial, anti-inflammatory, sun-protective, whitening, or anti-aging cosmeceuticals, depending on the effectiveness of the selected ingredient(s) [3,6].

Differently from the usual cosmetics, they do not contain preservatives, emulsifiers, colors, and other chemicals, therefore being more skin-friendly and respectful of nature.

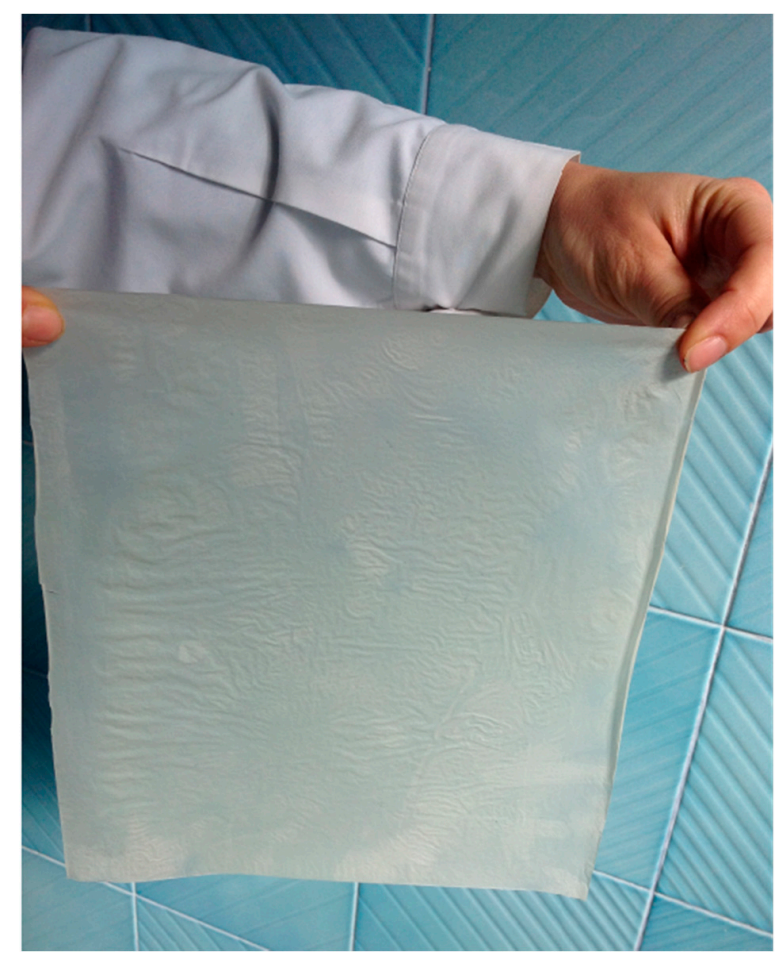

Figure 1. Example of chitin nanofibrils tissue obtained by electrospinning technology.

These dry facial masks, applied on wet skin (where they get wet and remain in contact for about $30 \mathrm{~min}$ ), are able to slowly release the active ingredients entrapped into the fibers, depending to the 
designed tissue-architectures. In turn, these innovative tissues also seem able to modulate the activity of the skin enzymatic microbiota, consisting of about 1 trillion units [22-24].

It is interesting to underline that these tissues not only act as carriers (thus loading and releasing the active ingredients at the different skin layers) but also possess a proper own effectiveness. They are made by chitin and lignin that are polymers characterized by an antibacterial, antioxidant, anti-inflammatory, regenerative, and protective activity. Thus, they protect the skin against environmental attack and pollution, such as UV and air micro and nanoparticulate (np) [12,13,24-26]. Therefore, they can be considered new active carriers for innovative cosmeceuticals, as they are useful for the consumer to ameliorate skin wellness both for men and for women and for the industry to increase its business.

\section{Bionanotechnology and Industrial R\&D Innovation}

While R\&D is at the base of innovation and society growth, the science is necessary for continually making progress. Nevertheless, it is difficult to imagine growth without innovation. According to Buscema and Pieri [27], "research and technological innovation are as the spoken and the written language". The first discovers new lands, while the second make roads and buildings for people to live. On the one hand, basic and experimental research represents the prime requirements for progress, designing criteria for producing scientific knowledge. On the other hand, the applied research is the bridge between basic and industrial research [27]. Thus, "innovation comes from the basic research, develops itself by the applied research and starts to produce by the industrial research" [27].

Therefore, industrial research should transform applied research in technology and innovative products, because they represent the inevitable outcome for company survival [28]. Innovation, in fact, involves the creation and diffusion of new products, processes, and methods, providing the creation of new business and new jobs, necessary for productivity growth. Consequently, the connection of people to one another, exchanging knowledge and results about innovative bionanotechnologies associated with advanced materials, are transforming the production, jobs, and location of all the economic activities $[27,29]$. This is the reason innovative economies are more resilient, more adaptable to change, and better able to support higher living standards [29,30]. For these reasons, in the last 20 years, in the industry, the greatest evolution of molecular biology and bionanotechnology from the academic laboratory to manufacturing processes has occurred in both pharmaceutical and cosmetic fields. Therefore, the consequential current and upcoming technical knowledge are playing and will continue to play an increasing and innovative role for the cosmetic industries dedicated to skin, hair, and nail care. Thus, on the one side, these innovations can improve the potential safety of products, while on the other side, the functionalities they impart to the product remain a critical component to be assessed. In this context, bionanotechnology and bioeconomy are showing a great increasing trend, because they are based on the use of safe biopolymeric ingredients $[29,30]$. In fact, these natural compounds, which are obtained by waste materials and sustainable processes, have been shown to reduce or eliminate the generation of substances hazardous to humans, animals, plants, and the environment [31]. In addition, this positive trend is also motivated by the urgent demand of consumers for healthy living and "green" consumption. Thus, the "natural" has generated a wide-ranging discussion encompassing products with ecocredentials, sustainable sourcing, and clean labels [31]. Therefore, prevention and wellbeing are driving innovation beyond cosmetics. They are supported by smart technologies that are rapidly catapulting forward the desired life styles.

\section{Biopolymers from Nature}

A biopolymer is a natural, inexpensive, and degradable biomaterial produced by monomers produced by living organisms. These monomeric units are covalently bound to form polymeric larger structures [32,33]. These compounds, which represent the majority (about 75\%) of all organic material on earth, are mainly in the form of polysaccharides that are used by living organisms as food storage or structural material. They consist prevalently of structural materials, such as cellulose 
and lignin, or reserve material, such as starch, obtained from plant biomass, or chitin extracted from fishery byproducts, or glycogen use as storage compound from animals. All these ingredients, apart from glycogen, can be used to produce nonwoven innovative tissues, films, and other useful goods. They can be simply extracted by plants or obtained alternatively by the biosynthesis of monomers, recovered from natural sources $[33,34]$. Just to remember, starch is one of the most common dietary sources for human beings as well as one of the main storage polysaccharides for plants. Cellulose and lignin, in fact, represent the most abundant organic substances present in the plant kingdom.

Chitin, the most abundant polysaccharide recovered in nature after cellulose, is the main structural material constituting the exoskeleton of various invertebrates, also surrounding the plasma membrane of plant, fungal, algal, and bacterial cells (but not animal). Finally, glycogen is the storing carbohydrate of an animal's body. In conclusion, all polysaccharides are widely found in the biosphere, fulfilling important functions in living organisms, such as energy storage and structural resistance [33]. Their large-scale production from renewable sources and their intensive use from the consumers will contribute to replacing the nonbiodegradable petroleum-based compounds and to saving the ecosystem of our planet for the upcoming generations.

\section{The Cosmetics and Active Ingredients Market}

Before describing the characteristics and functionalities of the proposed innovative cosmetics made by natural fibers and nonwoven tissues, it is useful to report some market data on the cosmetic-product classes requested from consumers and the active ingredients used for their formulation. Increased demand for anti-aging, moisturizing, skin-whitening, and products protective against the sun rays and pollutants, coupled with the increasing aged population and the demand for more functional ingredients, are driving the cosmetic market worldwide [34]. While the active ingredients value chain starts with the procurement of raw material required for cosmetic manufacturing, its use depends on the type of cosmetic. However, the ingredients used by the cosmetic manufacturers generally comprise a single chemical or a mix of two or more chemicals for the specific function they have to perform. Thus, the EU and the USA are projected to be the largest markets of these ingredients during the forecast period 2016-2026 because of the high per capita spending power on cosmetic products by their consumers. Pacific Asia and Latin America are expected to be the most promising regions in terms of increment and opportunity lying ahead for generating high revenues. Moreover, the cosmetic market, expected to continually increase between 2016 and 2026, is dominated by skin care application, because of the growing awareness among consumers about their skin health [34]. Thus, the anti-aging agent segment is expected to witness the highest compound annual growth rate (CAGR) between 2016 and 2026, driven by baby boomers. In fact, they are using more anti-aging cosmetic products to care for and slow down wrinkles and fine lines and to control the full aging processes. Other categories of active ingredients requested from consumers include cleaning, soothing, and self-tanning agents, as well as anti-oxidant, emollient, and anti-acne agents. Lastly, the interest in products able to protect skin and hair from the negative impact of pollutants is also increasing. According to a WHO report [35], in fact, from 2016, over 3 million people die annually due to their negative effects on health. It has been shown that excessive exposure to environmental pollutants has a negative impact on human skin and health in general, causing premature aging and exacerbating symptoms of dermatological diseases, such as acne, atopic dermatitis, and psoriasis [36-38]. Indoor and outdoor air particulates, in fact, by weakening the skin-barrier function and penetrating the skin layers, can also result in systemic toxicity. Nevertheless, it must be noted that while human exposure to outdoor emissions is from $\sim 10,000 \mathrm{np}$ ( $\mathrm{np}=$ nanoparticles) to $\sim 50,000 \mathrm{np} / \mathrm{ml}$ air, that to indoor ones is from $\sim 10,000 \mathrm{np}$ to $\sim 240,000 \mathrm{np} / \mathrm{ml}$ air.

For the same reasons, the growing demand for men's grooming cosmetics has increased the request for hair care products based on innovative natural and active ingredients [39]. This is the reason the conditioning agent segment accounted for the largest share of the market in 2015, through a request of products at low cost, possibly of natural origin, and with a wide applicability. Regardless, 
specialized and natural ingredients able to confer a performance benefit to a formulated innovative product, are sold on comparatively low volumes and at higher prize, when compared with commodity products $[39,40]$. Thus, such cosmetics are marketed for their performance characteristics and not for their chemical content or origin. For all these reasons, the cosmetic ingredients market was evaluated at US\$2.63 billion in 2015 and is projected to reach US\$4.45 billion by 2026 at a CAGR of $5.2 \%$ from 2016. On the other hand, the global cosmetic market stood at US $\$ 460$ billion in 2014 and is estimated to reach US $\$ 675$ by $2020[40,41]$. The highest cosmetic consumption in the world has been registered in South-East Asia with 31.7\%, the USA and the EU with 20.6\%, South Americas with 13.5\%, and Russia, Africa, and Australia with 6.7\% [39,40]. For the skin care market as well as for the active ingredients, purchasing decisions are increasingly motivated by the request for healthy green cosmetic products, skin-friendly and respectful of the environment. It is interesting to underline that the cosmetic niche market, such as the facial sheet masks, stood at US\$6.21 billion in 2017, and it is estimated to reach 10.4 billion by 2023 with a CAGR worldwide of $8.9 \%$ between 2016-2024, while in China and East Asia, yearly growth registered an impressive rate of 29\% in the period 2011-2016 [31,39-41]. The growing consumer demand for these face masks is connected to the request for cosmetic products that are easy to use, with a loutish texture that feels like paper, and which are effective as anti-aging products, possibly classified as green, and offered at an accessible price [41-43]. Due to these new market tendencies and the increasing request for more green cosmetics from the consumer, introduction into the market of innovative cosmeceuticals made and distributed as biodegradable nonwoven masks seem quite promising [41-43].

\section{Chitin Nanofibrils and Nanolignin to Make Renewable Fabrics}

\subsection{Chitin}

As previously reported, chitin, as the second polysaccharide and renewable carbon source present in nature after cellulose with a production of about 1 trillion tons per year, is one of the most used natural materials to make polymeric fibers and engineered tissues [44]. Present in predominant alpha form, it is a polymer composed of Beta-(1,4)-linked N-acetyl-glucosamine linear units, resulting in long antiparallel polymeric chains forming nanofibers, resembling the structure of hyaluronic acid (Figure 2) [45]. In fact, it was postulated that chitin can be an ancestral precursor of hyaluronan synthesis at the level of plasma membrane [45]. However, during its synthesis, chitin polymers anneal to one another to form fibers of high tensile strength (Figure 3) [46,47]. The fibers, ordered in a laminated structure, are frequently reinforced by cross-linking with proteins, minerals, and waxes. Thus, they can be found in different shapes and functions as fungal cell walls, crustacean exoskeletons, insect cuticles, and butterfly wings (Figure 4) [48,49]. However, alpha-chitin occurs in crustaceans in the predominant crystalline form with a polygonal section profile, consisting of 18-25 molecules with a diameter of 2 and $5 \mathrm{~nm}$ and lengths of about $300 \mathrm{~nm}$ [45-49].

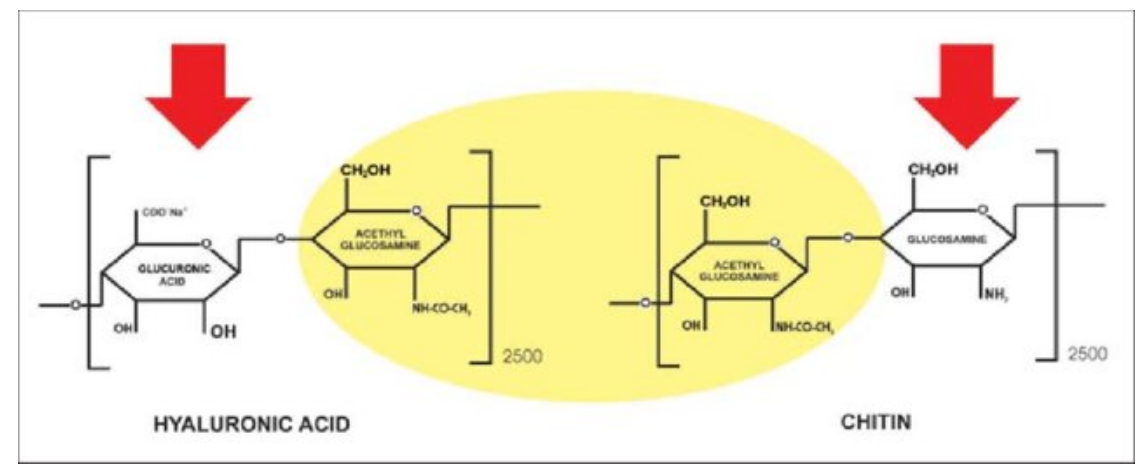

Figure 2. Chitin resembles the hyaluronic acid structure. 


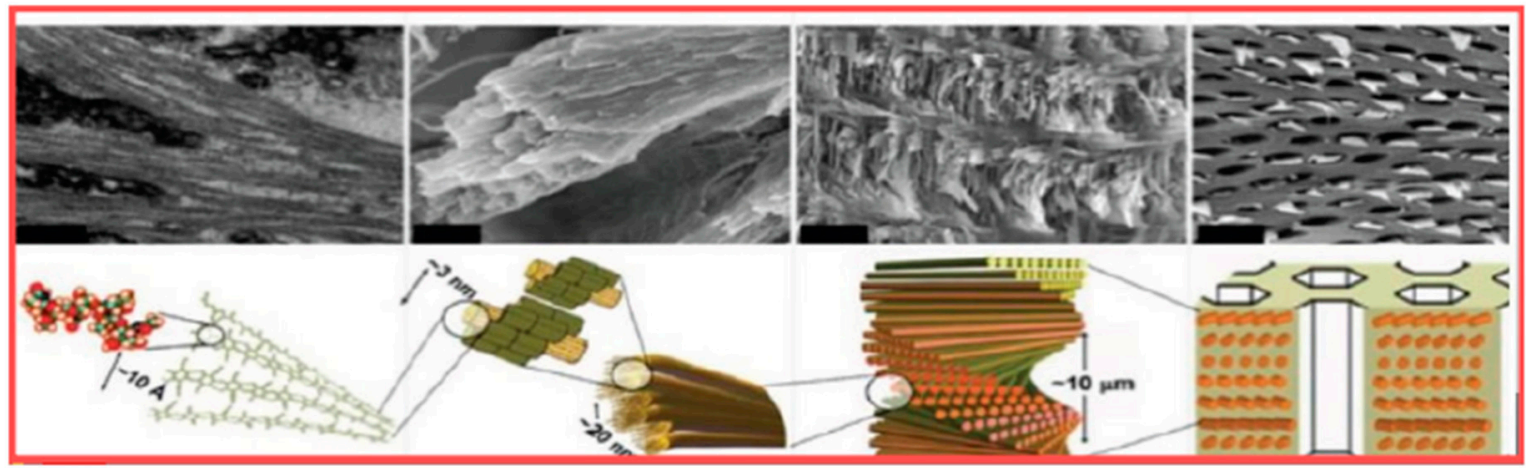

Figure 3. Chitin polymer organization (courtesy of Svetoslan et al. [46].

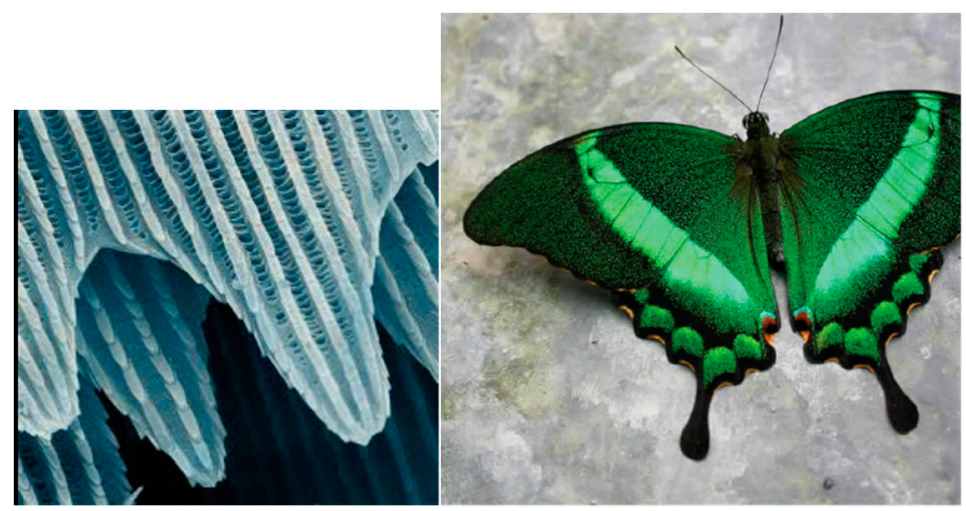

Figure 4. Structure organization of chitin in a butterfly wing.

Chitosan is the deacetylated derivative of chitin, and both polymers are distinguished from one another by their degree of acetylation (DA), which reflects the relative proportion of N-acetylglucosamine: Chitin has a DA greater than 50\%, while for chitosan, DA is lower (Figure 5). Thus, chitin and chitosan encompass a family of linear polymers containing beta-(1,4)-linked glucosamine and variable levels of N-acetyl glucosamine, which reveal different properties, depending from the sources of the raw materials and the modality of the industrial process selected. Moreover, chitin- and chitosan-based nanoparticles have high binding power with atoms with empty orbital, such as those of metals, thanks to their large number of lone-pair electrons. Both polymers, therefore, may have biomedical applications. In fact, they are hemostatic compounds able to enhance immunization activity and the skin's wound-healing capacity, and they also show biocompatibility, biodegradability, and adsorption properties that are considerably higher than those of synthetically modified cellulose [50-52].

Regarding nanoparticle toxicity [53], chitin nanofibrils (CNs) used as a carrier and produced by an ecofriendly circular technology at zero waste in our lab (data not reported-patent pending), showed no toxicity and resulted in growth compatible with ] human keratinocytes ]. Similar results were obtained for chitin-lignin nanoparticles $[13,53,54]$. It has been also evidenced that chitin is metabolized by human and environmental enzymes to a linear polysaccharide used from the cell as nutrition or as energy for its further reduction to oxygen [55-57].

On the other hand, lignin has shown different biological activities because of the presence of phenolic compounds in its structure [57]. Moreover, being biocompatible with human cells, it is also considered safe, skin-friendly, and environmentally friendly in its nanoform [25,58,59].

In addition, nanochitin, nanolignin, and their complexes promote cell growth and skin repair, supporting natural extracellular matrix (ECM) by the increased production of defensin- 2 and modulation of the metalloproteinase activity, without releasing secondary toxic ingredients $[13,24,25,54,55]$. 


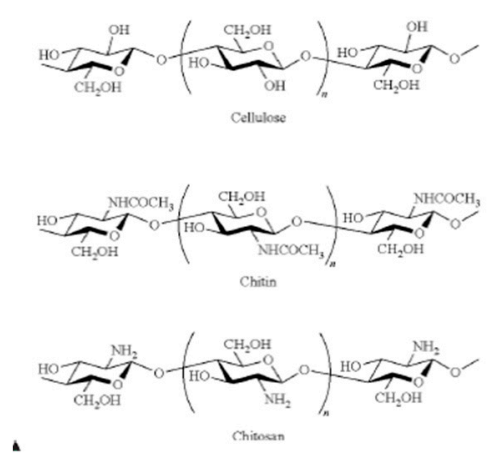

Figure 5. Chitin and chitosan chemical structure compared to cellulose.

It is also important to underline that chitin showed a different capacity in modulating the inflammatory cascade with dependence not only on the $-\mathrm{NH}_{2}$ and $-\mathrm{OH}$ groups present in the structure, but also on its size: smaller chitin fragments ( $<40$ micrometers) induced production of cytokines inhibiting tissue inflammation, modest-sized fragments (40-70 micrometers) induced a pro-inflammatory response, and larger ones are reported to be relatively inert (Figure 6) $[60,61]$. Moreover, it was shown that not only is this natural polymer easily metabolized from the human chitotriosidases to produce glucosamine, acetyl glucosamine, and glucose (that are used from human cells as nutritive compounds or energy), but these enzymes also prefer to catabolize the acetylated chitosan units versus the non-acetylated ones [55].

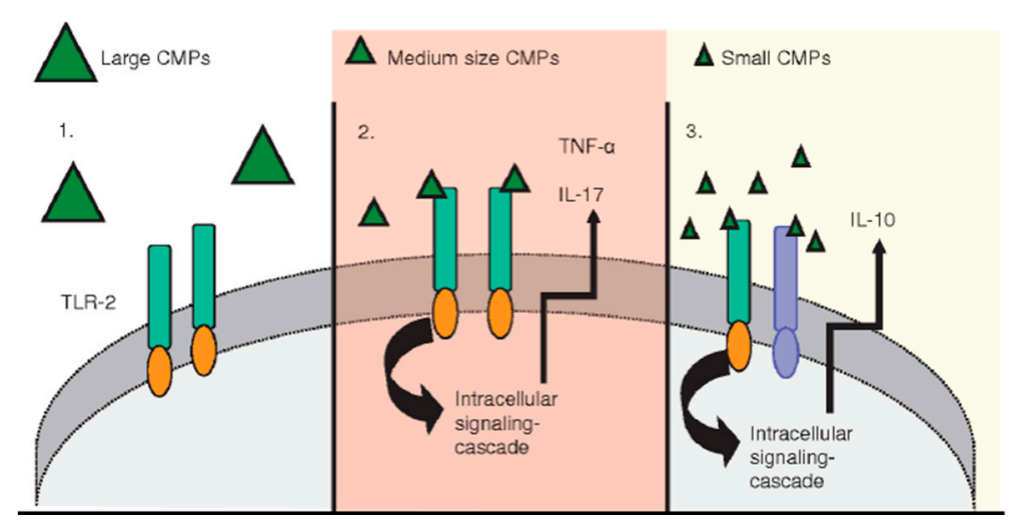

Figure 6. Pro-inflammatory and anti-inflammatory activity of chitin is a function of its dimension [61].

For these reasons, chitin nanofibrils (CNs) were selected to make nonwoven tissues to produce biodegradable facial masks and advanced medications. In fact, they were shown not only to possess a good anti-inflammatory activity $[12,13,62]$ for their nanosize dimension, but also to be more easily catabolized because they are richer in acetylated units when compared to chitosan [55].

However, acting as protective coating and structural support, chitin is a structural polymer that makes up the cell walls of fungi as well as the exoskeleton of insects and crustacean shells, while it resembles keratin in the human counterpart [63] (Figure 7). However, while on the one hand, this natural polymer seems not to be synthesized by plant and mammalian, on the other hand, its molecular structure can be recognized by chitinases and chitotrioidases, which bind and actively degrade chitin and chitinase-like proteins. In this way, they are active against chitin-bearing pathogens [55].

Moreover, chitin stimulates macrophage activation in mammals, regulating both inflammation and tissue remodeling and helping to provide a more efficient healing process. Thus, plants express chitinases in response to fungal infection, which is part of some pathogenesis-related protein families. Similarly, mammalian innate immune cells, such as macrophages or neutrophilic granulocytes, secrete acidic chitinases or chitotriosidases $[22,23,55,56]$. It is interesting to underline that the role 
of chitotriosidases inside macrophages is not only limited to their chitinolytic activity against the engulfed chitin containing organisms or to innate immunity. They are also implicated in the activation and polarization cascades of macrophages, as well as in the indirect activation of other immune cells $[24,56,62]$.

However, these enzymes develop important processes, such as remodeling the fungal cell wall and shedding the old crustaceans' cuticle, thus allowing to annually recycle billion tons of chitin/chitosan from the environment.
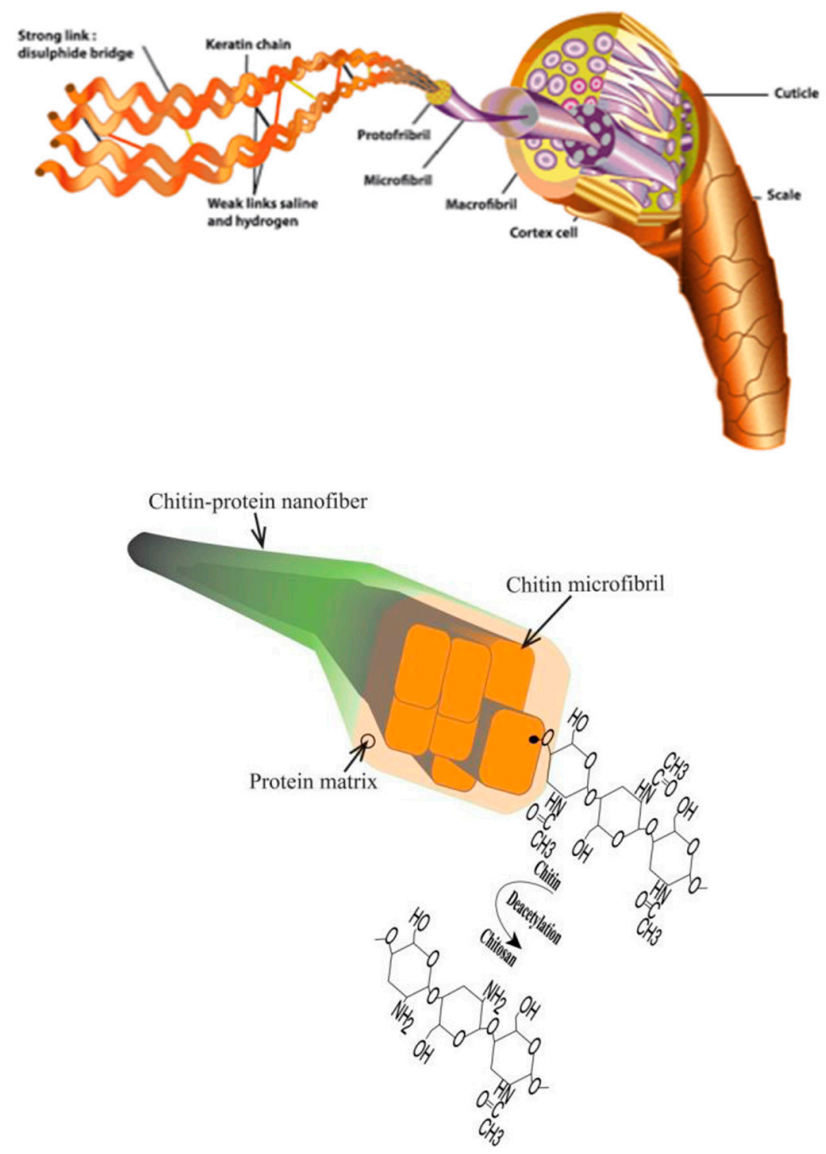

Figure 7. Chitin resembles the function of keratin in mammals [63].

For this purpose, it is to remember that about $75 \%$ of the total weight of crustaceans, ending up as byproducts of the fishery industry, is the cause of great environmental and human hazard. In fact, seafood wastes are generally thrown away at sea, burned, land-filled, or simply left out to spoil (Figure 8) [64]. Thus, the extraction of chitin from shells could be a way not only to minimize the waste, but also to produce goods, such as the innovative biodegradable nonwoven fabric [63,64].

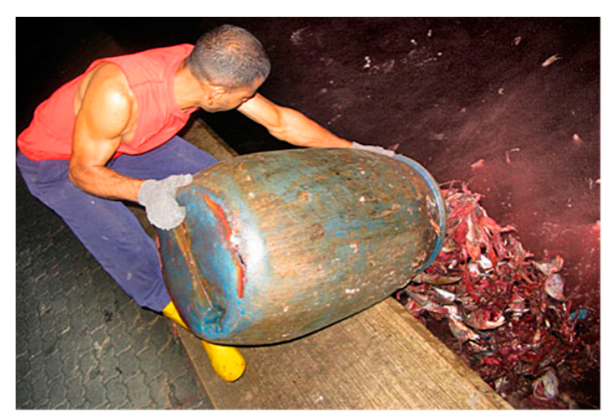

Figure 8. Seafood waste is pervasive throughout the sea and filled in land. 


\subsection{Lignin}

Lignin [65] is present in significant amounts in trees and accounts for $15-25 \%$ of herbaceous biomass. It is a natural and renewable material available at an affordable price. It is a poly-aromatic macromolecule with a reported worldwide production of around 100 million tons per year, obtained as a byproduct of cellulose production in pulp and paper processing $[22,66]$.

It is a highly branched polyphenolic polymer derived from three phenyl propane units, consisting of monolignols such as p-coumaryl alcohol, coniferyl alcohol, and sinapyl alcohol connected by aromatic and aliphatic ether bonds (Figure 9) [65,67]. Lignin, which is covalently linked to certain polysaccharides in plant cell walls to form the so-called lignin-carbohydrate complexes, has a fundamental structural and defensive role against the pathogen aggressions. In fact, it provides water resistance to the cell wall and plays a central role in the development of vascular plants and indirectly for all the higher forms of life on Earth [67].

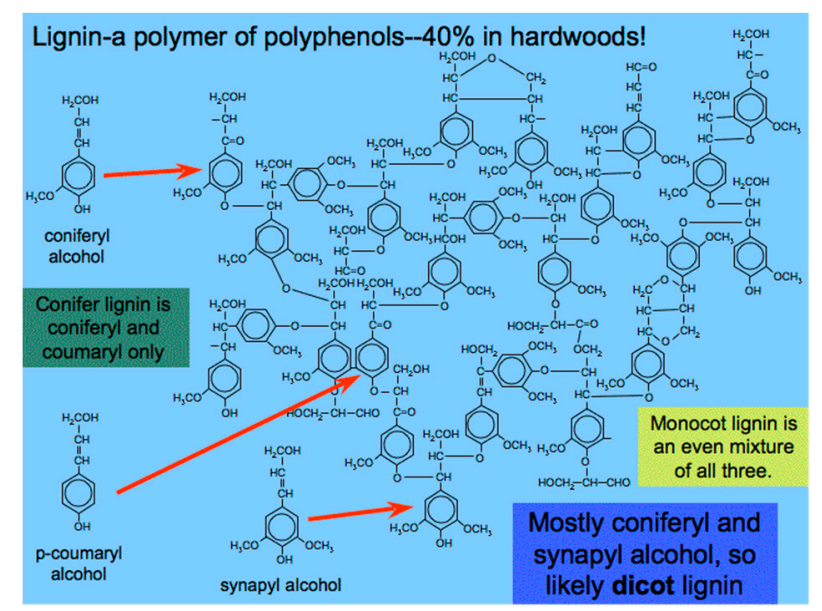

Figure 9. Chemical structure of lignin.

It is possible to easily produce lignin nanoparticles (LGs) (i.e., nanolignin) thanks to its peculiar structure. In fact, its hydrophobic part (phenylpropanoid units) aggregates to form the micelle core in the water solution, while its hydrophilic part (phenolic and aliphatic hydroxyl groups) forms the micelle shell [65,67]. Aromatic rings and methoxyl groups, in fact, characterize the hydrophobic parts of lignin and, at a molecular level, these are scattered around the hydrophilic aliphatic and phenolic $\mathrm{OH}$ groups [68-70]. Therefore, lignin nanoparticles might be promising alternatives for producing functional polymer composites [71,72], characterized for their UV shielding and antioxidant properties due to the phenolic hydroxyl groups. Therefore, their preparation, offering unique properties for the increased surface area, has attracted interest in the field of biomedicine and cosmetics. Thus, lignin nanoparticles can be used for drug delivery systems, or to enhance the UV barrier and increase the antioxidant and antibacterial properties, for example, of films and nonwoven tissues [12,13,70-72], or for the protective role they and their derivatives play against the development of different diseases.

\section{Bionanocomposites and Nonwoven Tissues}

To produce biodegradable nonwoven tissues for beauty face masks used as innovative cosmeceuticals, it is necessary to make biopolymeric nanocomposites obtained by natural polysaccharides. Just to remember, a nanocomposite is a system made by combining two constituents, a reinforcement (or filler) and a matrix, which, acting in unison and retaining their individual characteristics, exhibit better engineering properties [71]. Chitin nanofibrils can be used as reinforcement of biopolymer-based bionanocomposites [72] but can also be used to produce nanostructured fibers by electrospinning. Thus, it is possible to produce nonwoven tissues through electrospinning technology (Figure 10) using a gel of natural polysaccharides blended with chitin nanofibrils-lignin (CN-LG) nanostructured particles 
that are used both as filler and active agents. By blending and stirring two or more biopolymers, such as nanolignin and nanochitin complexed and bound to selected active ingredients, it was possible to produce nonwoven tissues made by activated micro/nanofibers imparting skin effectiveness and safeness.

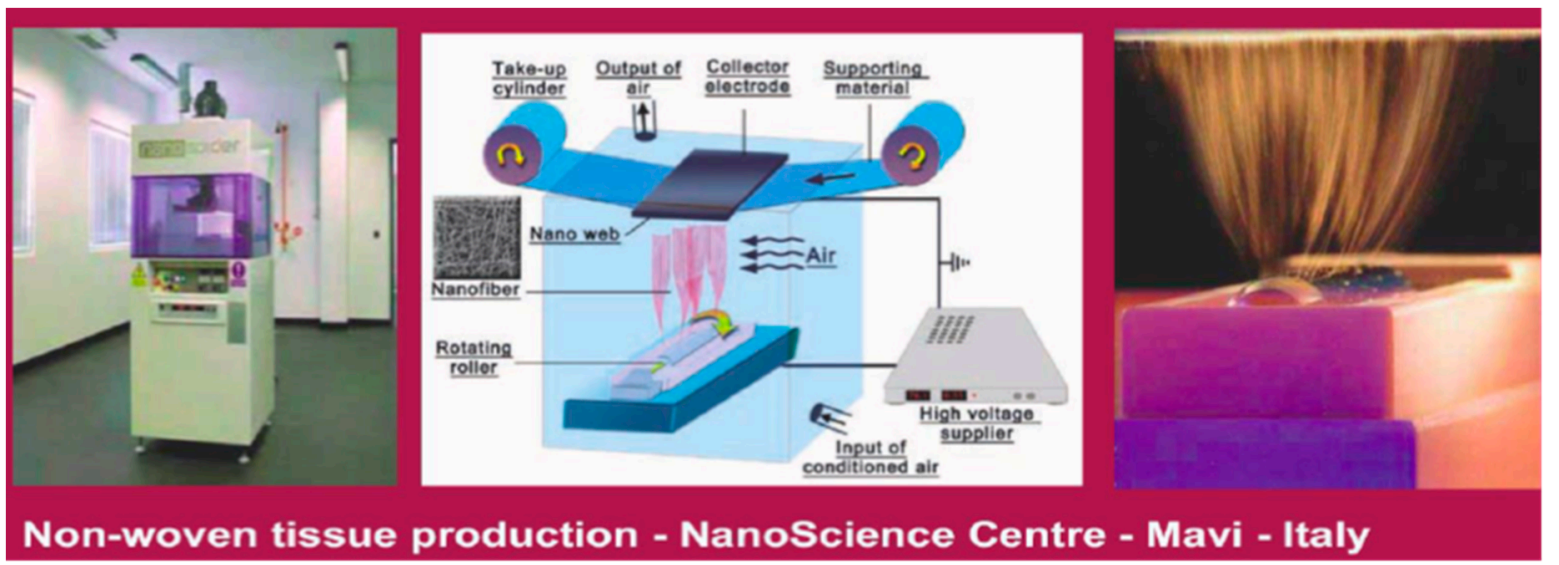

Figure 10. Electrospinning technology.

Because of their small size, these nanofibers can be applied to the skin by tissues designed as specific controlled diffusion systems and can easily interact with its structure, releasing the active ingredients and interacting with the biomolecules present on the surface and inside the cells. Furthermore, a gel, composed of chitin nanofibers (CN) and nanolignin (LG) complexed by the gelation method (Figure 11), has been electrospun with polyethylene oxide (PEO), chitosan, and collagen polypeptides $[12,13,24]$.

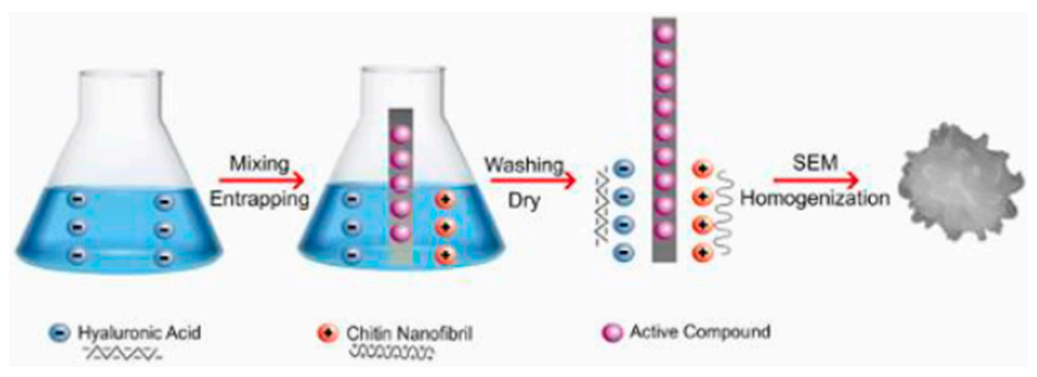

Figure 11. The gelation method.

Through the gelation method, the $\mathrm{CN}$ suspension (positively charged) is slowly mixed-at room temperature and by mechanical stirring - with LG (negatively charged), resulting in spherical micro/ nanoparticles (Figure 12), readily formed at different sizes and surface charges (Figure 13) [59,71-73] because of the complex action between the positive and the negative charges involved. Before starting the electrospinning, CN-LG are bound to selected active ingredients. The collagen peptides were shown to promote cell adhesion and proliferation, while chitin nanofibrils, nanolignin, and chitosan could facilitate skin adhesion and the release of the active ingredients, modulating the keratinocytes turnover and acting as an anti-inflammatory, immunomodulatory, and cell antioxidant system $[12,13,24]$.

Electrospinning is a method of fabricating long nanofibers from a viscous polymer solution [71,73], and it allows to prepare nanofibers and tissues of high mechanical resistance from organic or inorganic materials. The obtained tissue-engineered scaffolds aim to induce tissue regeneration by engineering the behaviors of the skin individual cells $[73,74]$.

The scaffold architecture, which is necessary to guide cell morphology and proliferation, must be properly designed for restoring the local microenvironment and obtaining the requested and desired 
biological functions. Moreover, these innovative nonwoven tissues can also serve as a reservoir system able to gradually release specific biological signals.
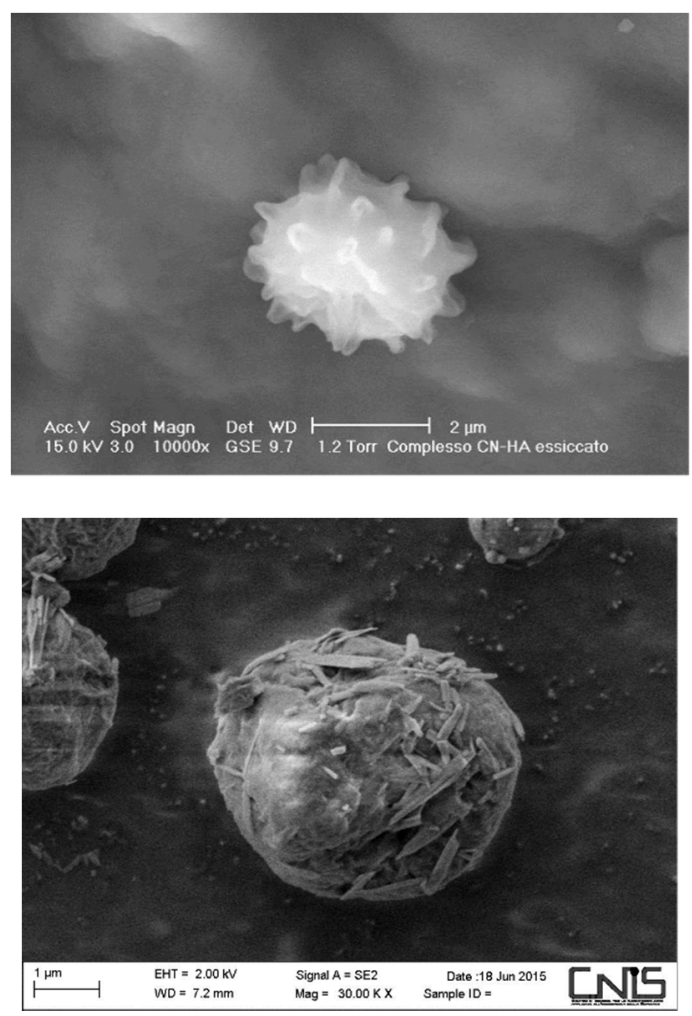

Figure 12. Nanoparticles of chitin nanofibrils-hyaluronan (on top) and chitin nanofibrils-lignin (below).

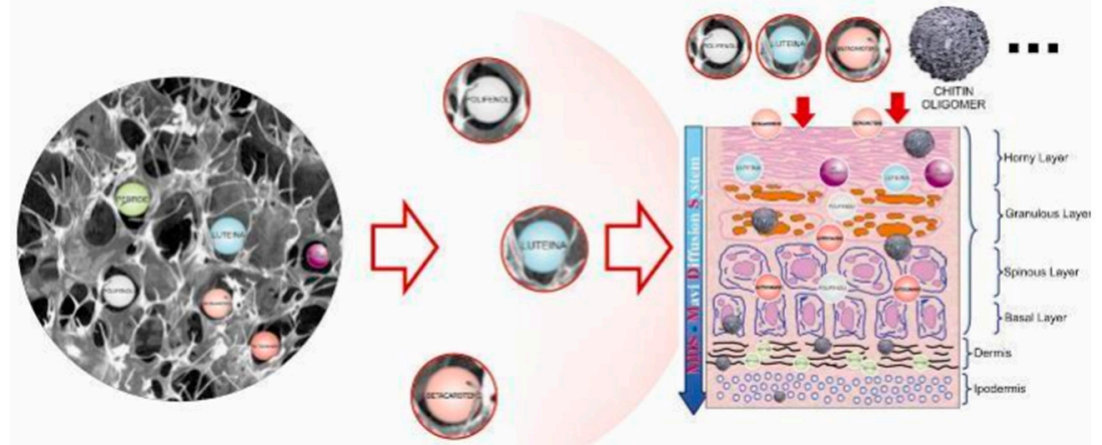

Figure 13. The nanoparticle surface charges influences skin penetration.

However, as previously reported, for obtaining a real skin-effectiveness from these nonwoven tissues, different and selected active ingredients must be entrapped into the $\mathrm{CN}$ fibers before the electrospinning procedure. These ingredients results are necessary to produce innovative and effective cosmeceuticals that can be used, for example, for anti-aging (Figure 14) [75] and whitening treatments (Figure 15) [76], or to control greasy and dandruff hair (Figure 16) [77], as well as to repair the skin barrier (Figure 17) [78] or to act as UV protective and anti-bacterial agent (Figure 18) [79]. It is interesting to underline that both CN and LG are able not only to act as a carrier that loads the selected ingredients entrapped into the fabric, but also as proper and effective active ingredients. 


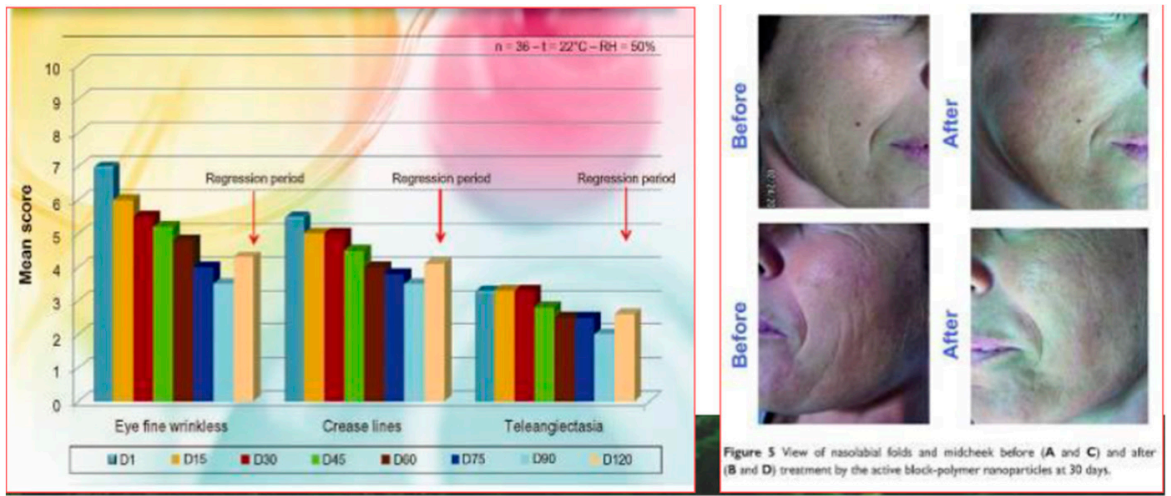

Figure 14. Anti-aging activity of chitin nanofibril [77].

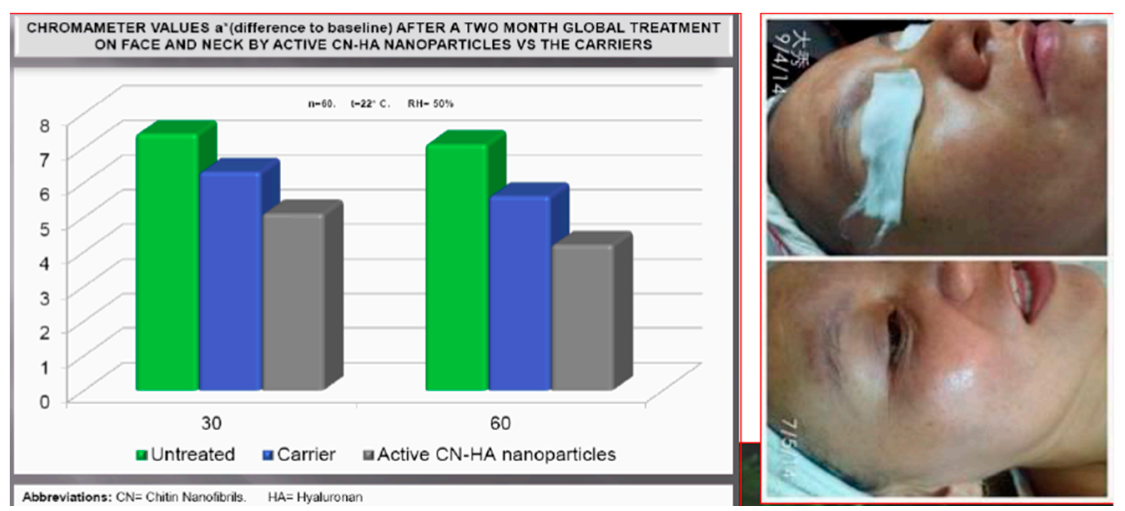

Figure 15. Whitening activity of chitin nanofibril-lignin entrapping active ingredients [76].

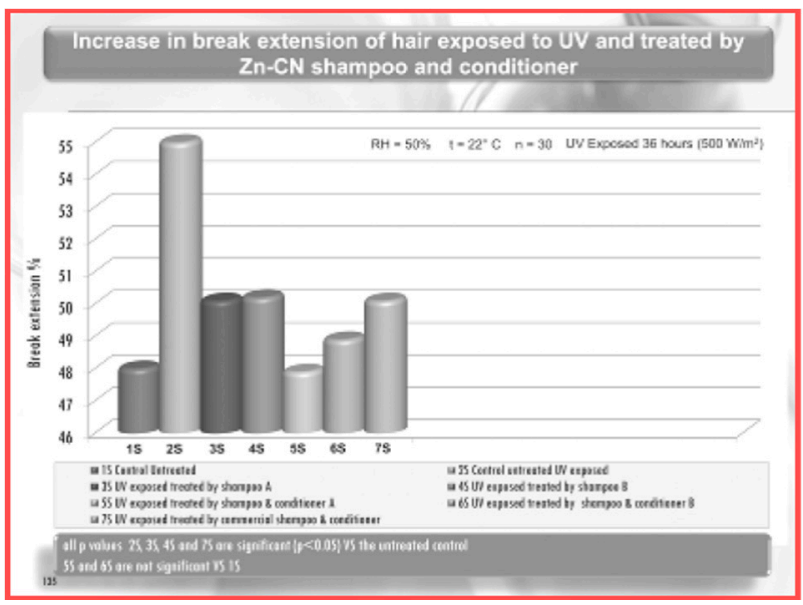

Figure 16. Activity of chitin nanofibril-lignin for hair treatment [77].

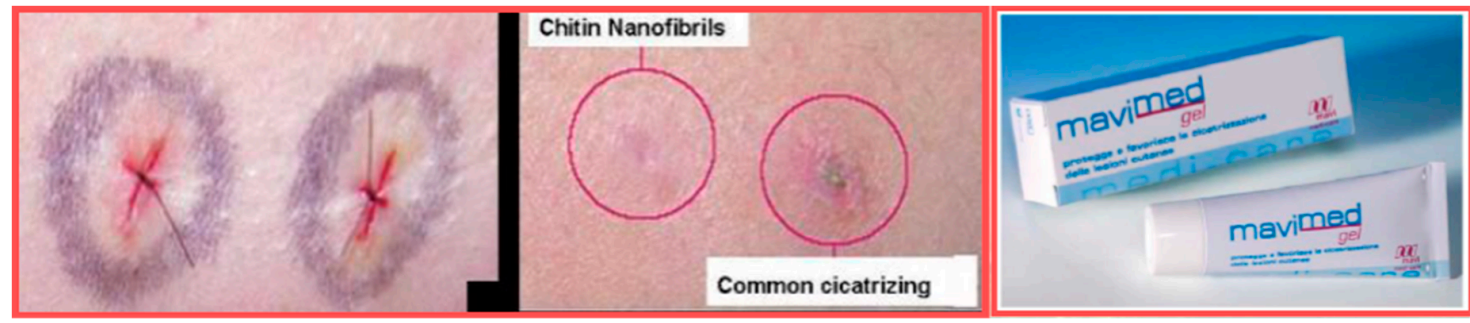

Figure 17. Skin barrier repairing activity of chitin nanofibrils [56]. 


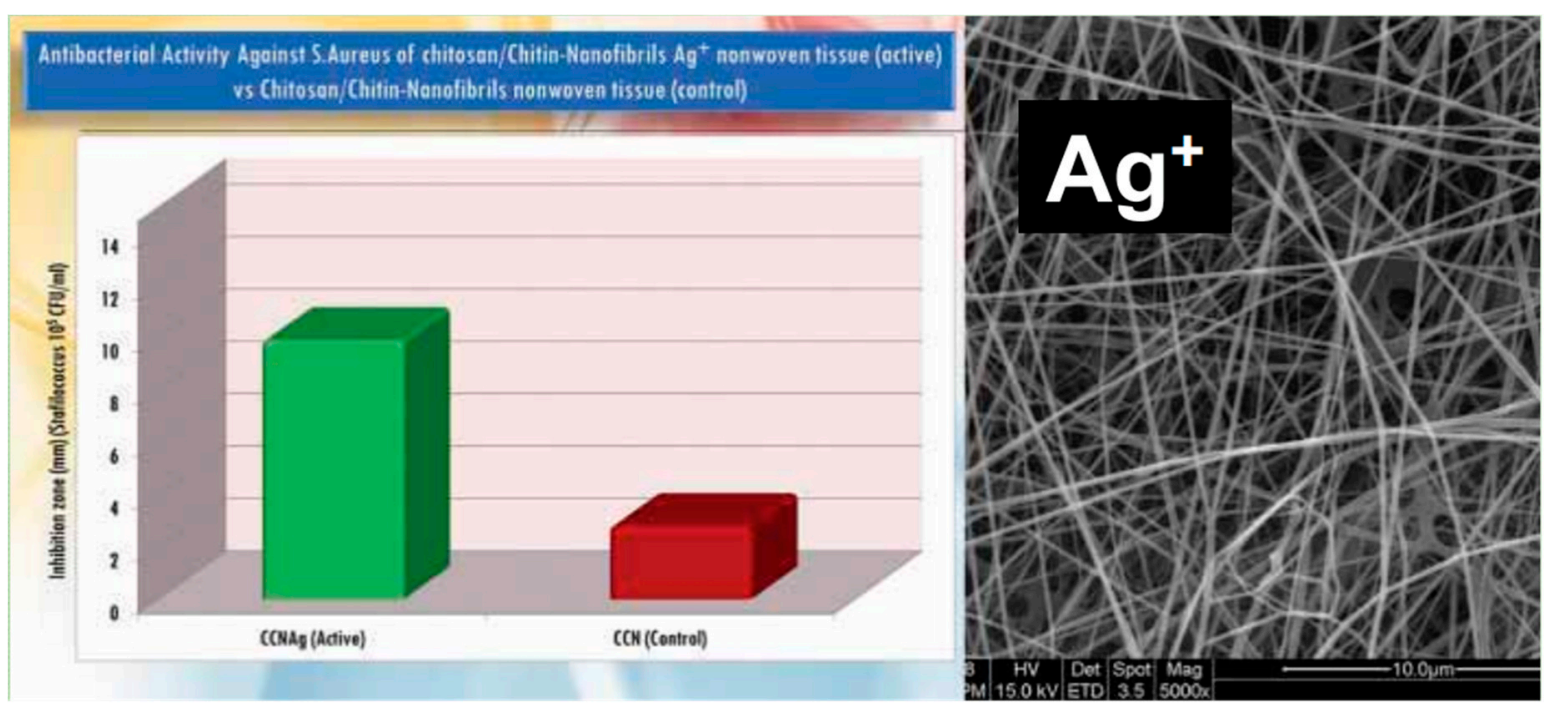

Figure 18. Antibacterial activity of chitin nanofibrils bound to nanostructured silver [56].

As previously reported, $\mathrm{CN}$ results are safe, healthy, and nontoxic because they are easily metabolized to release glucosamine, acetyl glucosamine, and glucose, used as food and energy from human cells [53-56]. On the other hand, LG releases polyphenolic units, which are active as antioxidant, immunomodulant, and antibacterial compounds $[67,68,70]$.

\section{Conclusions}

The pursuit of prevention and wellbeing together with respect for the environment are driving innovation beyond cosmetics. On the one hand, consumers are seeking personalized products respecting nature and obtained through smart technologies. On the other hand, they are also reallocating their interests to premium products that, if characterized by an affordable price, could better fulfill their needs and priorities. Moreover, beauty masks, considered part of the visit in wellness centers (SPAs), represent for the consumer the possibility to access a luxurious and relaxation treatment with the same skin benefits, obtainable from beauty center treatments. The reported and described cosmeceutical tissues could give the same benefits to the consumer, with the advantage of remaining at home. This is the reason $47 \%$ of Chinese females used at least one type of facial mask in the morning in the six months to January 2017, while Asia Pacific accounted for $76 \%$ of global sheet masks launches in 2016 [80]. From 40 to 50\% of the new facial masks launched in South Korea and Japan reported an anti-aging claim, while only $25 \%$ claimed the same in China. However, $47 \%$ of female facial mask consumers (aged 20-49 in 2017) used these special cosmetics with pore-refining purposes, while 39\% used them to reduce fine lines and wrinkles. In addition to Asia-Pacific countries, analysts have identified other emerging economies such as Indonesia, Argentina, Brazil, and India as lucrative markets for sheet face masks for the next few years. Thus, it seems necessary to offer to consumers different skin care benefits in a convenient manner and a short turnaround time, capturing their imagination and proposing innovative natural products made by new technologies, as the reported cosmeceutical fabric. For all these reasons, these innovative cosmeceutical tissues, being free of preservatives, emulsifiers and other chemicals and totally biodegradable, could be considered safer end ecofriendly.

In conclusion, through this technology, it seems possible to create a new and innovative category of cosmeceuticals, engineered as nonwoven biodegradable tissues and able to restore and regenerate structure and function of aged, photoaged or diseased skin. Naturally, the effectiveness and safeness of these innovative cosmetics must be controlled by in vitro and in vivo methodologies, as reported, for example, in one of our recent studies $[53,54]$. The integration of this new technology with the urgent 
requests from the consumers of effective and ecofriendly cosmetics free of side effects, able to slow down the signs of aging and maintain a juvenile appearance, could represent a real future innovation.

Author Contributions: Conceptualization, P.M.; writing — original draft preparation, P.M.; writing-review and editing, M.B.C.; supervision, P.M.; funding acquisition, P.M.

Funding: This research was partially funded by the EU, grant number 745839, through the funding of the POLYBIOSKIN project.

Acknowledgments: We thank Biobased Industries and Horizon 2020 for the received fund for the research project PolyBioSkin which was necessary to go on with these studies. Moreover, we thank MAVI Sud (Italy) and CIMV (France) for the obtained samples of chitin nanofibrils and biolignin, respectively.

Conflicts of Interest: The authors declare no conflict of interest.

\section{References}

1. Schueller, R.; Romanowski, P. Beginning Cosmetic Chemistry; Allured Publishing Co.: Carol Stream, IL, USA, 2003.

2. Schueller, R.; Romanowski, P. Multifunctional Cosmetics; Marcel Dekker, Inc.: New York, NY, USA, 2003.

3. Epstein, H. Skin Care Products. In Cosmetic Science and Technology; Barel, A.O., Paye, M., Maibach, H.I., Eds.; Informa Healthcare: New York, NY, USA, 2009; pp. 121-134.

4. Council Directive 76/768/EEC of 27 July 1976. On the Approximation of the Laws of the Member States Relating to Cosmetic Products. OJEC n. 1. 262/169.27.9.1976 (and Following Amendments), Official Journal of the European Communities. Available online: https:/ / eur-lex.europa.eu/legal-content/EN/TXT/PDF/ ?uri=CELEX:31976L0768\&from=HU (accessed on 11 February 2019).

5. Regulation (EC) No 1223/2009 of the European Parliament and of the Council, November 302009 on Cosmetic products, Official Journal of the European Union. Available online: https://ec.europa.eu/ health/sites/health/files/endocrine_disruptors/docs/cosmetic_1223_2009_regulation_en.pdf (accessed on 11 February 2019).

6. Morganti, P.; Paglialunga, S. EU Borderline cosmetic products: Review of current regulatory status. Clin. Dermatol. 2008, 26, 392-397. [CrossRef]

7. Reed, E. The definition of "cosmeceuticals". J. Soc. Cosmet. Chem. 1962, 13, 103-116.

8. Kligman, A.M. Why cosmeceuticals? Cosmet. Toilet. 1995, 108, 37-40.

9. Skechers, J.W. Cosmetic: Are crossing the final barrier into Dermatology. J. Appl. Cosmetol. 2007, 25, 1-10.

10. Sivamani, R.V.; Jagdeo, J.; Elsner, P.; Maibach, H.I. Cosmeceuticals and Active Cosmetics: Drugs Versus Cosmetics, 3rd ed.; Tailor\& Francis: New York, NY, USA, 2015.

11. Ames, N.S.; Ranucci, A.; Moriyama, B.; Wallenberg, G.R. Understanding the 16SrRNA Gene in Translational Nursing Science. Nurs. Res. 2017, 6, 184-197. [CrossRef]

12. Morganti, P.; Del Ciotto, P.; Stoller, M.; Chianese, A. Antibacterial and Anti-inflammatory Green Nanocomposites. Chem. Eng. Trans. 2016, 47, 61-66.

13. Morganti, P.; Fusco, A.; Paoletti, I.; Perfetto, B.; Del Ciotto, P.; Palombo, M.; Chianese, A.; Baroni, A.; Donnarumma, G. Antiinflammatory, Immunomodulatory and Tissue Repair Activity on Human Keratinocytes by Green Innovative Nanocomposites. Materials 2017, 10, 843. [CrossRef] [PubMed]

14. Renner, G.; Aufebert, F.; Burfeindt, J.; Calvet Carhths-Perifan, M. Cosmetic Europe Guidelines on the Management of Undesirable Effects and Reporting of Serious Undesirable Effects from Cosmetics in the European Union. Cosmetics 2017, 4, 1. [CrossRef]

15. Cornell, E.; Kwa, M.; Pallet, A.S.; Xu, S. Adverse events reported to the Food and Drug Administration from 2004 to 2016 for cosmetics and personal care products marketed to newborns and infants. Pediatr. Dermatol. 2018, 35, 225-229. [CrossRef] [PubMed]

16. Inetianbor, J.E.; Yakubu, J.M.; Zeonu, S.C. Effects of Food Additives and Preservatives on man-a Review. Asian J. Sci. Technol. 2015, 6, 1118-1135.

17. Soni, M.G.; Carabin, I.G.; Burdock, G.A. Safety assessment of p-Hydroxy benzoic acid(parabens). Food Chem. Toxicol. 2005, 43, 986-1015. [CrossRef]

18. Paszkiewicz, W. Parabens: Food Preservatives and Consumer Safety. Med. Weter. 2015, 71, 553-556. 
19. Muse, H.P.; Frost, S.; Ohund, U.; Foscn, K.E. Allergic contact dermatitis from octylthiazolinone. Contact Dermat. 2013, 69, 49-52. [CrossRef] [PubMed]

20. Isaksson, M.; Hauksson, I.; Hindsen, M.; Ponten, A.; Svedman, C.; Bruze, M. Methylisothiazolinone Contact Allergy is Rising to Alarming Heights also in Southern Sveden. Acta Derm. Venereol. 2015, 96, 32-34.

21. Aerts, O.; Goossen, A.; Lambert, J.; Leopoittevin, J.P. Contact Allergy Caused by Isothiazolinone Derivatives: An Overview of non-cosmetic and unusual cosmetic sources. Eur. J. Dermatol. 2017, 27, 115-122. [CrossRef] [PubMed]

22. Elmonem, M.A.; van de Heuvel, L.P.; Levtchenko, E.N. Immunomodulatory Effects of Chitotriosidase Enzyme. Enzyme Res. 2016. [CrossRef] [PubMed]

23. Sender, R.; Fuchs, S.; Milo, R. Revised Estimates for the Number of a Human and Bacteria Cells in the Body. PLoS Biol. 2016, 14, e1002533. [CrossRef] [PubMed]

24. Morganti, P.; Stoller, M. Chitin and Lignin: Natural Ingredients from Waste Materials to Make Innovative and Healthy Products for Humans and Plant. Chem. Eng. Trans. 2017, 60, 319-324.

25. Vinardell, M.P.; Mityans, M. Lignins and Their Derivatives with Beneficial Effects on Human Health. Int. J. Mol. Sci. 2017, 18, 1219. [CrossRef]

26. Beisl, S.; Friedl, A.; Miltner, A. Lignin from micro-to Na-nosize: Applications. Int. J. Mol. Sci. 2017, $18,2367$. [CrossRef]

27. Buscema, M.; Pieri, G. Ricerca Scientifica e Innovazione; Rizzoli: Milano, Italy, 2003.

28. Braconier, H.; Nicoletti, G.; Westemore, B. Policy Challenges for the Next 50 Years. OECD Economics Department Policy Papers N 9, Paris, France. 2014. Available online: www.oecd.org (accessed on 14 March 2018).

29. OECD, Innovation Strategy 2015. 2015, An Agenda for Policy Action. Meeting of OECD Council at Ministerial Level, Paris, France, 3-4 June. Available online: www.oecd.org (accessed on 11 February 2019).

30. Mulhaupt, R. Green Polymers Chemistry and Bio-Based Plastics: Dreams and Reality. Chem. Phys. 2013, 214, 159-174. [CrossRef]

31. Miscallef, N. Reimaging Growth in the Global Beauty; Euromonitor International: Aberdeen, UK, 2017.

32. Rai, R.; Roether, J.A.; Knowles, J.C.; Mordan, N.; Roy, I. Highly Elastomeric Poly(3-hydroxy octanoate) Based Natural Polymer Composite for Enhanced Keratinocyte Regeneration. Int. J. Polym. Mater. 2018, in press.

33. Benkeblla, N. Polysaccharides: Natural Fibers in Food and Nutrition; CRC Press: New York, NY, USA, 2014.

34. M\&M. Active Ingredients Market for Cosmetics by Functionality Magarpatta, Maharashtra, India. 2018. Available online: www.marketsandmarkets.com (accessed on 19 March 2018).

35. WHO. Ambient Air Pollution: A Global Assessment of Exposure and Burden of Disease; World Heath Organization: Geneva, Switzerland, 2016.

36. English, J.S.; Dawe, R.S.; Ferguson, J. Environmental effects and skin disease. Br. Med. Bull. 2003, 68, 129-142. [CrossRef] [PubMed]

37. Kim, E.K.; Kim, S.; Lee, J.H.; Han, Y.; Kim, Y.M.; Kim, G.B.; Jung, K.; Cheong, H.K.; Ahn, K. Indoor air pollution aggravates symtoms of atopic dermatitis in children. PLOS ONE 2015, 10, e0119501.

38. Kim, K.E.; Cho, D.; Park, H.J. Air pollution and skin diseases: Adverse effects of airborne particulate matter on various skin diseases. Life Sci. 2016, 152, 126-134. [CrossRef] [PubMed]

39. US Commercial Service Hong Kong. Cosmetic \& Toiletries Market Overviews 2015; Country Commercial Guide and Industrial Report; USA-International Trade Organization: New York, NY, USA, 2016.

40. Gerstle, T. Asia Personal Care E Cosmetic Market Guide 2016; Country Commercial Guide and Industrial Report; USA-International Trade Organization: New York, NY, USA, 2016.

41. Morganti, P.; Coltelli, M.B.; Danti, S. Biobased tissues for innovative cosmetic products: PolyBioSkin as an EU Research Project. Glob. J. Nanomed. 2018, 3. [CrossRef]

42. Kwek, S. The Facial Masks Remain a Covered Item among Urban Chinese Consumers; Mintel Global New Products Database: London, UK, 2017.

43. GIA Inc. Chitin \& Chitosan: A Global Strategic Business Report; Global Industry Analists Inc.: New York, NY, USA, 2018.

44. Stern, R.; Jedrzejas, M. Hyaluronic asset: Their genomical structure and mechanisms of action. Chem Rev. 2006, 106, 818-839. [CrossRef] [PubMed]

45. Ige, O.O.; Umoru, L.E.; Aribo, S. Natural Products: A Minefield of Biomaterials. ISRN Mater. Sci. 2012. [CrossRef] 
46. Svetoslav, N.; Petrov, M.; Lymperkis, L.; Friak, M.; Sachs, C.; Fabritius, H.O.; Raabe, D.; Negeubaues, J. Revealing the Deign Principles of High-Performance Biological Composites using Ab initio and Multiscale Simulations: The example of Loabster cuticle. Adv. Mater. 2010, 22, 519-626.

47. Morganti, P. Biomimetic Materials Mimicking Nature at the Base of EU Projects. J. Sci. Res. Rep. 2014, 3, 532-544. [CrossRef]

48. Qu, T.; Verma, D.; Alucozai, M.; Toman, R. Influence of Interactions on Deformation Mechanism and Interface Viscosity in a Chitin-Calcite Interfaces. Acta Biomater. 2015, 25. [CrossRef] [PubMed]

49. Bueter, C.L.; Specht, C.A.; Levitz, S.M. Innate Sensing of Chitin and Chitosan. PLoS Pathog. 2013, 9, e1003080. [CrossRef]

50. Muzzarelli, R.A.A.; El Mehtedi, M.; Mattioli/Belmonte, M. Emerging Biomedical Applications of Nano/Chitins and Nano-Chitosans Obtained via Advanced Eco-Friendly Technologies from Marine Resources. Mar. Drugs 2014, 12, 5468-5502. [CrossRef] [PubMed]

51. Zhao, D.; Yu, S.; Sun, B.; Gao, S.; Guo, S.; Zhao, K. Biomedical Applications of Chitosan and Its Derivative Nanoparticles. Polymers 2018, 10, 462. [CrossRef]

52. Crisponi, G.; Nurchi, V.M.; Lachowicz, J.I.; Peana, M.; Medici, S.; Zoruddu, M.A. Toxicity of Nanoparticles: Etiology and Mechanisms. In Antimicrobial Architectonics from Synthesis to Applications; Grumezescu, A., Ed.; Elsevier: New York, NY, USA, 2017; pp. 512-537.

53. Morganti, P.; Palombo, M.; Carezzi, F.; Nunziata, M.L.; Morganti, G.; Cardillo, M.; Chianese, A. Green Nanotechnology Bioeconomy Serving: Natural Beauty Masks to Save the Environment. Cosmetics 2016, 3, 41. [CrossRef]

54. Donnarumma, G.; Fusco, A.; Morganti, P.; Palombo, M.; Anniboletti, T.; Del Ciotto, P.; Baroni, A.; Chianese, A. Advanced Medications made by Green Nanocomposites. Int. J. Res. Nano Sci. 2018, 5, 261-270.

55. Eide, K.B.; Norberg, A.L.; Heggset, E.B.; Lindbom, A.R.; Varum, K.M.; Eijsink, V.G.H.; Sorlie, M. Human Chitotriosidase-Catalyzed Hydrolosis of Chitosan. Biochemistry 2012, 52, 487-495. [CrossRef] [PubMed]

56. Morganti, P.; Carezzi, F.; Del Ciotto, P.; Morganti, G.; Nunziata, M.L.; Gao, X.H.; Chen, H.D.; Tischenko, G.; Yudin, V.E. Chitin Nanofibrils: A Natural Multifunctional Polymer. Physicochemical characteristics, effectiveness and safeness. In Nanobiotechnology; Phoenix, D.A., Waqar, A., Eds.; One Central Press: Manchester, UK, 2014; pp. 1-37.

57. Martinez, V.; Mitjans, M.; Binardell, M.P. Pharmacological Applications of lignins and lignins related compounds: An overview. Curr. Organ. Chem. 2012, 16, 1863-1870. [CrossRef]

58. Kim, S.; Fernandes, M.M.; Matama, T.; Loureiro, A.; Gomes, A.C.; Cavaco-Paulo, A. Chitosan-lignosulfonates sono-chemically prepared Nanoparticles: Characterization and potential applications. Colloids Surf. B Biointerfaces 2013, 103, 1-8. [CrossRef] [PubMed]

59. Kumar Gupta, A.; Mohanty, S.; Nayak, S.K. Synthesis, Characterization and Application of Lignin Nanoparticles (LNPs). Mater. Focus 2014, 3, 444-454. [CrossRef]

60. Da Silva, C.A.; Chalouni, C.; Williams, A.; Hartl, D.; Lee, C.G.; Elias, J.A. Chitin is a size-dependent regulator of machrophage TNF and IL-10 production. J. Immunol. 2009, 182, 3573-3582. [CrossRef] [PubMed]

61. Brinchmann, B.C.; Bayat, M.; Brogger, T.; Muttuvelu, D.V.; Tjonneland, A.; Sigsgaard, T. A possible role of chitin in the pathogenesis of asthma and allergy. Ann. Agric. Environ. Med. 2011, 18, 7-12. [PubMed]

62. Lee, C.G.; Da Silva, C.A.; Dela Cruz, C.S.; Ahangari, F.; Ma, B.; Kang, M.J.; He, C.H.; Takyar, S.; Elias, J.A. Role of Chitin and Chitinase/Chitinase-Like Proteins in Inflammation, Tissue Remodeling, and Injury. Annu. Rev. Physiol. 2011, 73. [CrossRef] [PubMed]

63. Mushi, N.E.; Utsen, S.; Berglund, L.A. Nanostructured biocomposite film of high toughness based on native Chitin nanofibrils and chitosan. Front. Chem. 2014. [CrossRef] [PubMed]

64. Hamed, I.; Ozogul, F.; Regenstein, L.M. Industrial Applications of Crustacean by-products (Chitin, Chitosan and Chitooligosaccgarides): A review. Trends Food Sci. Technol. 2016, 48, 40-50. [CrossRef]

65. Qian, Y.; Deng, Y.; Qiu, X.; Li, H.; Yang, D. Formation of uniform colloidal spheres from lignin, a renewable resource recovered from pulping spent liquor. Green. Chem. 2014, 16, 2156-2163. [CrossRef]

66. Calvin-Flores, F.G.; Dobado, J.A. Lignin as renewable raw material. ChemSusChem 2010, 3, $1227-1235$. [CrossRef] [PubMed]

67. Henriksson, G. What are the biological functions of lignin and its complex action with carbohydrates? Nord. Pulp Pap. Res. J. 2017, 32, 527-541. [CrossRef] 
68. Tian, D.; Hu, J.; Bao, J.; Chandra, R.P.; Saddler, J.N.; Lu, C. Lignin valorization: Lignin nanoparticles as high-value bio-additive for multifunctional nanocomposites. Biotechnol. Biofuels 2017, 10, 192. [CrossRef] [PubMed]

69. Penna, M.J.; Mijajlovjc, M.; Biggs, M.J. Molecular level understanding of protein adsorption of the interface between water and a strongly interacting uncharged solid surface. J. Am. Chem. Sci. 2013, 135, 5323-5331. [CrossRef]

70. Beisl, S.; Miltner, A.; Friedl, A. Lignin from Micro- to Nano size: Production Methods. Mol. Sci. 2017, 18, 1244. [CrossRef] [PubMed]

71. Coltelli, M.B.; Cinelli, P.; Gigante, V.; Aliotta, L.; Morganti, P.; Panariello, L.; Lazzeri, A. Chitin Nanofibrils in Poly(Lactic acid)(PLA) Nanocomposites: Dispersion and Thetmo-Mechanical Properties. Int. J. Mol. Sci. 2019, 20, 504. [CrossRef] [PubMed]

72. Buragohain, M.K. Composite Structures; CRC Press: New York, NY, USA, 2017.

73. Kang, J.H.; Castano, O.; Kim, H.W. Electrospun materials as potential platforms for bone tissue engineering. Adv. Drug Deliv. Rev. 2009, 62, 1065-1083.

74. Keeney, M.; Han, L.H.; Onyah, S.; Yang, F. Tissue Engineering: Focus on the Musculoskeletal System. In Biomaterials Science; Rosen, Y., Elman, N., Eds.; CRC Press: New York, NY, USA, 2012; pp. 191-221.

75. Morganti, P.; Palombo, M.; Tishchenko, G.; Yudin, V.E.; Guarneri, F.; Cardillo, M.; Del Ciotto, L. Chitin-hyaluronan Nanoparticles to deliver Anti-aging Active Ingredients Through the Skin. Cosmetics 2014, 1, 140-158. [CrossRef]

76. Morganti, P.; Del Ciotto, P.; Carezzi, F.; Guarneri, F.; Yeo, Y.J. Skin Lightening Efficacy of New Formulations Enhanced by Chitin Nanoparticles Delivery System. Note I. J. Appl. Cosmetol. 2014, 32, 57-71.

77. Morganti, P.; Fabrizi, G.; Palombo, M.; Cardillo, M.; Cardillo, A.; Del Ciotto, P.; Carezzi, F.; Morganti, G. Activity of Chitin Nanofibrils Block-Copolymers Entrapping Zn/Al/SA/Allantoin on Seborrheic Dermatitis. A randomized double-blind placebo controlled study. J. Appl. Cosmetol. 2014, 32, 3-19.

78. Morganti, P.; Fabrizi, G.; Guarneri, F.; Palombo, M.; Palombo, P.; Cardillo, M.; Ruocco, E.; Del Ciotto, P.; Morganti, G. Repair Activity of Skin Barrier by Chitin-Nanofibrils Complexes. Sofw. J. 2011, 137, 10-26.

79. Morganti, P.; Morganti, G.; Morganti, A. Transforming Nanostructured Chitin from Crustacean Waste into Benefical Health Products: A Must of our Society. Nanotechnol. Sci. Appl. 2011, 4, 123-129. [CrossRef]

80. Jim, J. The Facial Mask Remains a Covered Beauty Item among Urban Chinese Consumers; Mintel Global New Product Database: London, UK, 2017. 